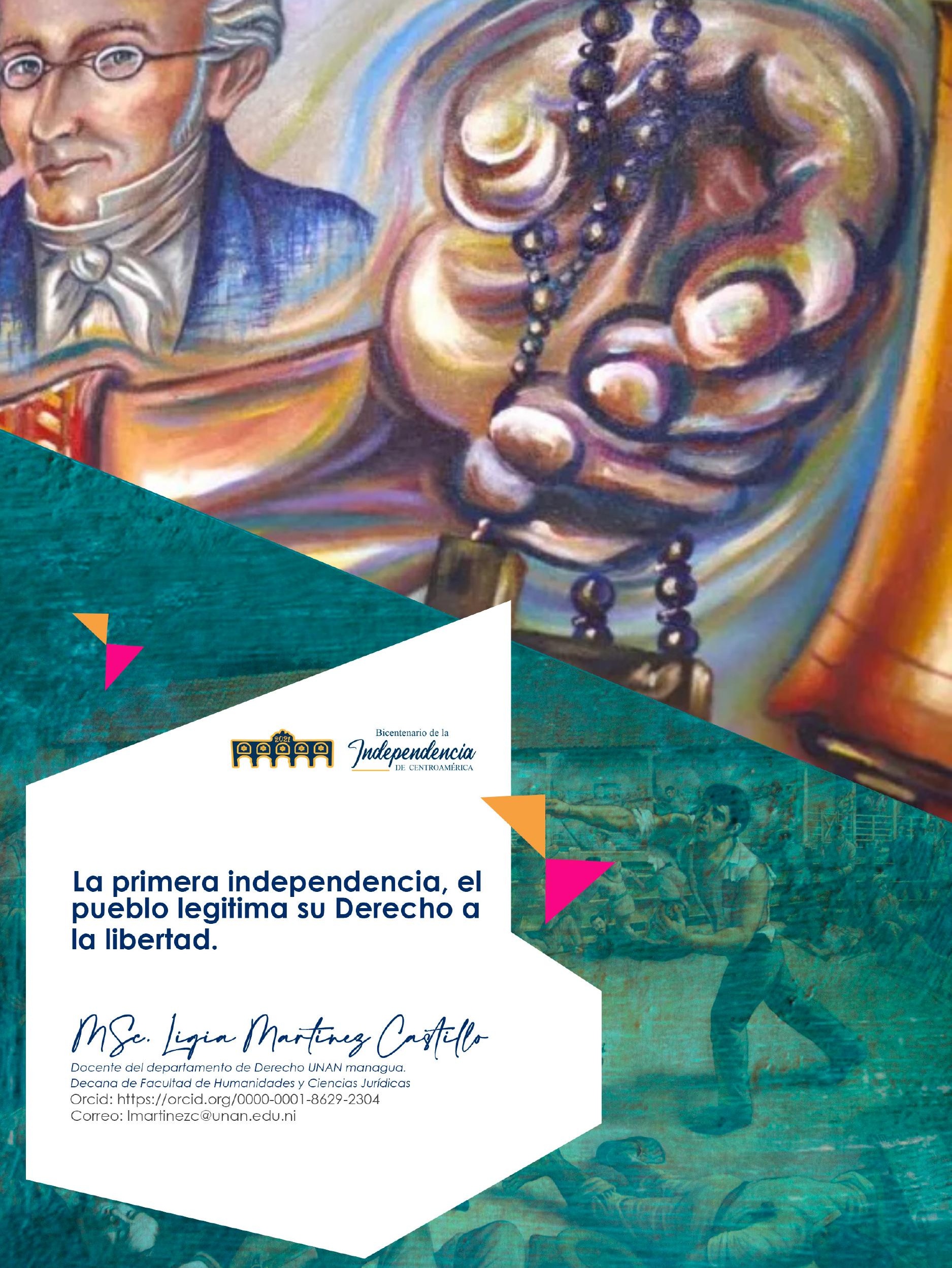




\section{La primera independencia, el pueblo legitima su Derecho a la Libertad.}

The first independence, the people legitimize their right to freedom

\section{RESUMEN}

La independencia es vista como un proceso que irrumpe la dominación colonial europea y específicamente española en Centroamérica, se denota que las acciones de los pueblos manifestaban el más ardiente deseo de revocar sus derechos usurpados, dada la arbitrariedad con que fueron gobernadas durante la colonia. El texto hace alusión a las acciones no tan pacíficas con que el pueblo participa, obligando a apresurar a las aristocracias criollas la firma del Acta de Independencia.

\section{PALABRAS CLAVE}

Pueblo, oligarquía criolla, independencia, soberanía, derecho del pueblo

Recibido: 25 mayo 2021 Aprobado: 02 de julio 2021

\section{SUMMARY}

Independence is seen as a process that breaks through the European and specifically Spanish colonial domination in Central America, it is denoted that the actions of the peoples manifested the most ardent desire to revoke their usurped rights, given the arbitrariness with which they were governed during the colony. The text alludes to the not so peaceful actions with which the people participate, forcing the Creole aristocracies to hasten the signing of the Act of Independence.

\section{KEYWORDS}

People, Creole oligarchy, independence, sovereignty, people's right 
Buenas tardes, Militantes sandinistas, Docentes, administrativos y estudiantes, un saludo revolucionario a todos los compañeros y cras que hoy nos acompañan a este lanzamiento de la Jornada del Bicentenario de la Independencia de Centroamérica que desde la Facultad de Humanidades y Ciencias Jurídicas y desde la Unidad de Victorias Electorales (UVE) Mildred Abaunza hacemos.

Este 2021 se cumplen 200 años de la firma del Acta de Independencia de Centroamérica en la ciudad de Guatemala, aquel 15 de septiembre de 1821. Debido a la arbitrariedad con que fueron gobernadas por el imperio español y la conducta que éste observó constantemente desde la conquista, excitó en los pueblos el más ardiente deseo de revocar sus derechos usurpados.

Sin duda, un acontecimiento de gran trascendencia histórica para los pueblos que conformaban la antigua Capitanía General de Guatemala por las consecuencias que traería ese hecho.

Por consiguiente, un documento polémico en su contenido alcance y efectos, que recoge de manera implícita las contradicciones y limitaciones de aquella "epopeya" emancipadora fraguada en un ayuntamiento, con escasa representación de las provincias, pero que será un referente "legal" para que todos los gobiernos locales se pronunciaran, desatando una cascada de acciones que convergieron en conflictos armados.

Como fue la SESIÓN de la firma del Acta del 15 DE SEPTIEMBRE DE 1821: Palacio Nacional de Guatemala, quince de septiembre 1821, Cito:

La junta se inició sin mayor retraso. El ambiente era tenso ante la importancia de lo que se habría de tratar y resolver. La reunión fue a puerta abierta, en el Real Palacio. Estaban alrededor de 50 personas en salón, pero en la antesala y en el corredor se reunieron cada vez más personas, lo mismo que en el patio, portales exteriores y en la plaza misma. Durante la lluviosa noche anterior se acudió a los barrios a fin de invitar al vecindario. Al principio la concurrencia no era muy nutrida, por lo cual Basilio Porras y Dolores Bedoya de Molina trataron de reunir más gente, pusieron música en la plaza y quemaron cohetes para atraer la atención del pueblo". Primero se dio lectura a los documentos llegados de Chiapas y a continuación se escuchó la opinión de los asistentes. Había diferentes puntos de vista, pues algunos querian que se proclamara la independencia y otros querian retardarla. Finalmente, como a las once de la mañana, se acordó redactar el Acta de Independencia por medio la cual Centro América se separaba de España. El Redactor de la misma fue el Lic. José Cecilio del Valle.

Este referente es seguido con detenimiento en la ciudad de Guatemala por sectores pro independencia y por aquellos no muy entusiastas de esta idea. Nuestro gran vecino del norte, Nueva España (México) meses atrás, había dado un paso adelante en la emancipación de la metrópoli ibérica y el desenlace de estos acontecimientos en México, acelera los procesos en América Central.

Luego de tensas negociaciones entre las élites locales de las provincias, no exentas de contradicciones, se anexan al naciente y efímero imperio de Iturbide. La experiencia trágica de la Federación Centroaméricana, es otro hecho histórico en esa larga fragua de la construcción de la identidad centroaméricana. 
Las guerras intestinas y la fragmentación de las antiguas provincias, convertidas en pequeños estados y/o naciones, sería el epílogo de una historia en común de dos siglos que culminan este 2021.

Al parecer la lucha libertaria no fue sólo entre los sectores del estrato blanco, sino que entre el grupo de los que eran favorecidos por el régimen colonial y el de los que sufrían grave perjuicio bajo ese régimen, pertenecientes a los grupos de color: indios, ladinos, negros y mulatos.

Por ello en lo personal me opongo a la opinión de que el pueblo no haya intervenido en la lucha por la independencia de Centro América. La visión de la "independencia pacífica" se contrasta con los enfrentamientos armados, que proliferaron en el área, antes y después de 1821.

En ocasión de conmemorar el bicentenario se hace necesario crear espacios para debatir y compartir puntos de vista, desde la academia, acerca del significado del acontecimiento haciendo un balance histórico, cultural, social, económico y político, de la situación de Centroamérica, sus logros y debilidades y en particular de Nicaragua, nuestro país.

Hay que recrear y enriquecer el proceso histórico de nuestro pueblo desde su independencia hasta nuestros días. Es por ello, que nuestra Facultad de Humanidades y Ciencias Jurídicas, invita a todas sus unidades académicas a la apertura de espacios que posibiliten estos debates entre los docentes, estudiantes y en general dentro de la comunidad universitaria.

De igual manera, es importante dar una mirada hacia las relaciones que mantenemos con nuestros vecinos hermanos centroamericanos y con aquellos más lejanos, en lo que respecta al respecto de los derechos de cada una de las naciones, promoviendo siempre ese espíritu de independencia, soberanía, dignidad, autodeterminación, sentimientos que nos caracteriza desde aquellos años de libertarios.

Hoy más que nunca hermanos y hermanas sandinistas necesitamos revitalizar todas esas convicciones con las que nos formamos como militantes para continuar levantando la bandera de lucha y no permitir que nos pisoteen fuerzas extranjeras bajo ninguna condición.

Para finalizar, expresar que sigue teniendo vigencia hoy más que nunca, el pensamiento de nuestro General de Hombres Libres Augusto Cesar Sandino: "La soberanía de un pueblo no se discute, se defiende con las armas en la mano". La Vice presidenta de Nicaragua, Cra Rosario Murillo: "Son tiempos para ratificar nuestra legitima, genuina y verdadera independencia".

\section{"A la Libertada por la Universidad"}

